\title{
The Impact of Demographic Variables and Consumer Shopping Orientations on the Purchasing Preference for Different Product Categories in the Context of Online Grocery Shopping
}

\author{
Haseba Hamad $^{1 *}$ Martin Schmitz ${ }^{2}$ \\ 1.Department of business management, Salahaddin university, Erbil, Iraq \\ 2.Researcher
}

\begin{abstract}
This study examines the impact of demographic variables and consumer shopping orientations on the purchasing preference for different product categories in the context of online grocery shopping within the UK. The data for this study was primarily collected from a web-based survey of consumers in the UK using a questionnaire. The quantitative data was enhanced by qualitative data in form of semi-structured interviews to enhance the quantitative results. A structural equation model (SEM) was used to analyse the quantitative data and to measure the relationships between the respective constructs. The findings show that the purchasing preferences vary by product category.
\end{abstract}

Keywords: Demographic Variables, Consumer Shopping Orientations, Product Categories, UK, and Structure Equation Modelling.

DOI: $10.7176 / \mathrm{JMCR} / 52-05$

\section{Introduction}

Over the past decade online shopping became a substantial and nearly indispensable part of today's fast lifestyle. Thus, a tremendous growth in the online shopping sector can be observed and the Internet is considered to be an important shopping venue by an increasing number of customers. According to (Nielsen UK, 2012), groceries represent the third biggest online shopping category in the UK. Online shopping provides a lot of benefits for the customers, since it substantially reduces search costs, grants convenient access to product and price information and enables the customer to easily compare products (Chu et al., 2010). Further, no travel costs or restrictions on shopping hours are involved in the buying process. Though, the demand for online shopping for products such as books, electronic devices and clothing is growing enormously; groceries are still facing difficulties to be sold online. Even though the online grocery shopping market is currently expanding in the UK, many customers are resisting to purchase groceries online (Hansen, 2004). Nevertheless, the UK has one of the most advanced online grocery markets in the world. The online grocery sales are currently accounted to $3.5 \%$ of total grocery sales in the UK. This number is predicted to almost double in the next few years to around 6\% in 2016 (Evolution, 2012). Although the online grocery sales are predicted to increase, this channel remains relatively small compared to alternative channels and groceries will still remain one of the most difficult objects to trade online. Therefore, companies have to tackle this challenge and develop strategies to make online grocery shopping easier, more accessible and finally more attractive and comfortable to meet the customer's expectations. If companies fail to do so they will be left behind and will be outperformed by their competitors. The four largest retailers of groceries in the UK have already established an online grocery shopping proposition. However, the penetration of the online channels remains still unsatisfying and leaves a lot of space for improvements to penetrate the customer even more. Yet, the companies have not been able to find a way to penetrate the online grocery sales to a high degree and profit from the economic advantage, which lies in this sector.In addition, many research have emphasised the decisive role of product categories on the online shopping behaviour (Bhatnagar et al., 2000; Liao and Cheung, 2001; Lian and Lin, 2008), but surprisingly only few studies have attempted to determine the influence of different product categories. Zhou et al. (2004) reported that the consumers' online shopping acceptance may vary among different product categories and Monsuwé et al. (2004) pointed out that some product categories are more suitable to be sold online than other categories. However, only few empirical studies have attempted to examine the role of product categories or limited their attention on one product category. Therefore this research focuses primary on demographic variables and the consumer shopping orientations and how these constructs affect the preference to purchase certain products online. These are considered to be the most influential factors that affect the online grocery shopping behaviour and are therefore subject of this research. As a result, the outcome of this research will provide a deeper understanding of consumers' demands in the context of online grocery shopping, which can be used to develop marketing strategies to penetrate the online grocery sales. 


\section{Literature review \\ 2.1 Demographic variables \\ 2.1.1 Gender}

Haque et al. (2007) and Hasan (2010) found that gender has significant influence on the online shopping behaviour of consumers. It is generally suggested that men are more likely to conduct online purchases more than women (i.e. Brown et al., 2003; Susskind, 2004). However, Goldsmith and Flynn (2005) reported that female consumers favour to purchase apparel online, which is contrary to the general assumption that men are more likely to conduct online purchases as suggested in other studies. According to this, the findings from previous studies have to be critically evaluated and it can be concluded that the effect of gender on the online shopping behaviour cannot be generalised and depends on different product categories. Consequently, additional effort is required to examine the impact of gender on the online shopping behaviour based on different product categories in the context of grocery shopping.

\subsubsection{Age}

It is generally suggested that the adoption of online shopping is negatively influenced by an increasing consumer age (i.e. Joines et al., 2003). Besides that, it is suggested that older consumers have a higher computer anxiety and are generally less familiar with information technology, which affects their acceptance of online shopping (Dholakia and Uusitalo, 2002). This view is supported by Sulaiman et al. (2008) who found that younger generations use online shopping more due to their knowledge of computer technology compared to older generations.

\subsubsection{Education}

Kim and Kim (2004) and Koyuncu and Lien (2003) indicate in their studies that better educated consumers are more likely to conduct online purchases on a regular basis. In addition, Burroughs and Sabherwal (2001) argued that education influences the acceptance and adoption of online shopping. Contrary to this, other researchers reported no relationship between education and the likeness to shop online (Bellman et al., 1999; Mahmood et al., 2004). This study included educational level in order to investigate its effect on the purchasing preference for different product categories to explain the phenomena of online grocery shopping.

\subsubsection{Household income}

Monsuwé et al. (2004) found a positive relationship between household income and the shop online. They suggested that consumers with higher household incomes are more likely to conduct online purchases compared to consumers with lower household incomes. In addition, Lohse and Spiller (2000) found that a higher household income is positively related to having access to online purchases.

\subsubsection{Marital status}

Hashim et al. (2009) found that divorced respondents are more likely to shop online compared to respondents who are either single or married. Brown and Venkatesh (2005) found also a positive relationship between marital status and online shopping. They suggested that married couples tend to have a higher household income due to their dual income. But it has to be considered that the generalizability on this issue is problematic, since it is questionable whether married couples have generally a dual household income. Apart from these findings, the literature regarding the impact of marital status on the online shopping behaviour is limited and rather scarce. However, subject of this present study is to investigate if the marital status influences the preference to purchase certain groceries online.

\subsubsection{Occupation}

The variable occupation is being considered in this study, since no previous research has examined the influence of occupation on the preference to purchase certain groceries online. It is believed that people with different occupations have different needs and consequently have different purchasing preferences for certain products (Armstrong and Kotler, 2003). Based on this view by Armstrong and Kotler (2003), this present study has the aim to reveal possible relations between the occupation and the preferred products purchased online.

\subsection{Consumer shopping orientations}

\subsubsection{Convenience-orientation}

Donthu and Garcia (1999) found that online shoppers are more convenience-oriented compared to traditional shoppers. In addition, Jarvenpaa and Todd (1997) reported that convenience is the most significant perceived benefit of online shopping. Moreover, Rohm and Swaminathan (2004) found that convenience-oriented shoppers have the highest propensity to purchase groceries online. Consequently, it can be concluded that convenience represents a significant consumer shopping orientation to conduct online purchases, particularly groceries.

\subsubsection{Price-orientation}

Zhou et al. (2004) suggested in their study that price-oriented consumers are always seeking to buy products for the lowest price or trying to get the best value for their expenses. Furthermore, Bakos (1997) found that online shopping significantly reduces search costs to get detailed information about prices and products. 


\subsubsection{Experiential-orientation}

Li et al. (1999) found that an experiential orientation negatively influences the likeness to conduct online purchases, since the experiential orientation focuses on interacting with products. Within the online environment it is not possible to experience the products, which means examining the physical condition of the product by touching, feeling or smelling it.

\subsubsection{Impulsiveness}

Donthu and Garcia (1999) found in their study on online shopping behaviour that Internet shoppers are more impulsive compared to non-internet-shoppers. In contrast, Girard et al. (2003) noted that impulsive purchases are more likely to be for inexpensive products seen in a physical store and concluded that impulsiveness is negatively related to the likeness to shop online. However, the findings on the impact of impulsiveness as a shopping orientation on the preference to purchase certain products online are limited. Therefore, it is subject of this study to determine what kinds of products are being preferred by impulsive-oriented online shoppers to be purchased online.

\subsubsection{Product categories}

Zhou et al. (2004) found that the consumers' online shopping acceptance may vary among different product categories .in addition, Monsuwé et al. (2004) suggested that some product categories are more suitable to be sold online than others. Further, Chu et al. (2010) pointed out that product categories such as food versus nonfood or sensory versus non-sensory have influence on the consumer shopping behaviour on the online channel. However, most research studies have limited their attention on one product category. It has to be mentioned that no earlier study has attempted to examine the role of product categories in the context of online grocery shopping in particular.

\section{Research framework and hypotheses}

\subsection{Research framework}

Based on the literature review the research framework was constructed (Fig. 1) to examine how specific demographic variables and consumer shopping orientations influence the purchasing preference for certain groceries online.

Figure 1: The conceptual framework

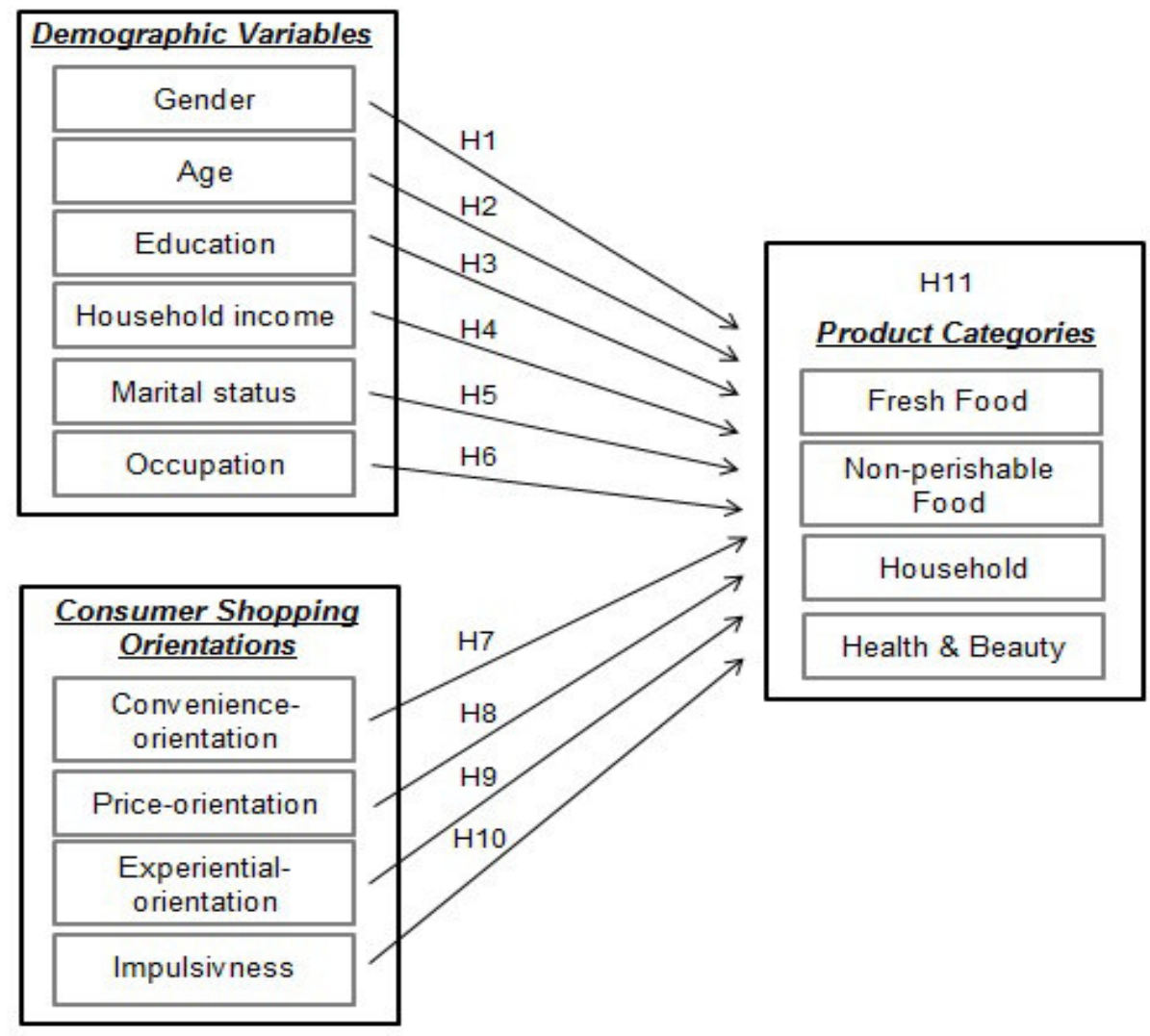




\subsection{Hypotheses}

Derived from the conceptual framework, the following hypotheses were created:

H1: There is a significant correlation between gender and the preference to purchase within certain product categories online.

H2: There is a significant correlation between age and the preference to purchase within certain product categories online.

H3: There is a significant correlation between education and the preference to purchase within certain product categories online.

H4: There is a significant correlation between household income and the preference to purchase within certain product categories online.

H5: There is a significant correlation between marital status and the preference to purchase within certain product categories online.

H6: There is a significant correlation between occupation and the preference to purchase within certain product categories online.

H7: Convenience-orientation significantly influences the preference to purchase within certain product categories.

H8: Price-orientation significantly influences the preference to purchase within certain product categories.

H9: Experiential-orientation significantly influences the preference to purchase within certain product categories.

H10: Impulsiveness significantly influences the preference to purchase within certain product categories.

H11: The demographic variables and consumer shopping orientations significantly influence the purchasing preference for different product categories.

\section{Methodology, study population and sample}

To validate the study conceptual framework this research employs mixed-method research in order to achieve the highest possible validity and reliability of the results. The quantitative data presented in this study were collected from a web-based survey of consumers in the UK using a self-administered questionnaire. This method was chosen, due to the fact that it is time and cost efficient compared to other distribution methods (Aaker et al. 2006). The sample consisted of 501 responses and was collected among consumers in the UK. Among the 501 responses $204(40.7 \%)$ participants indicated that they purchase groceries online on a regular basis. Structural equation modelling (SEM) was utilised to analyse the data collected .For collecting the qualitative data, six semistructured interviews with online grocery shoppers were conducted. The interviews were conducted via telephone or in person and took approximately 10 to 15 minutes.

Based upon previous measures and a review of the relevant literature multiple item scales were developed to operationalise each of the constructs shown in Fig. 1 (see Appendix 1).

Furthermore, the questionnaire of study was pre-tested twice (namely face validity and content validity) to ensure that the respondents will understand all the questionnaire items that used in this study easily. Next, the survey was piloted on a sample of 50 consumers in the UK. Cronbach's Alpha used to measure reliability of constructs, with a value at least 0.7 (Hair et al., 2010). While, 'corrected item-total correlation statistics` were used to determine which of the candidate variables and its indicators should be retained. Indicator with a' corrected item-total correlation 'value of 0.35 and higher were retained (Netemeyer et al., 2003). All items were found to be significant, reliable, and valid.

\section{Data analysis and results}

PLS-SEM was used to analyse the data collected. The SEM consists basically of (1) the measurement model (outer model); and (2) the structural model (inner model) (Garson, 2008; Gefen et al., 2000).

\subsection{Measurement model}

The measurement model examines the relationships between latent variables and their indicators (Hair et al., 2010). The measurement model includes test of the internal consistency reliability (Crobach's Alpha and composite reliability) and construct validity (convergent validity and discriminate validity) for latent variables. In this study, the measurement model was performed for the demographic variables gender, age, education, income, marital status and occupation; consumer shopping orientations convenience-orientation, priceorientation, experiential-orientation and impulsiveness and product categories fresh food, non-perishable food, household as well as health and beauty. As shown in Table 1, the Cronbach's $\alpha$ and composite reliability for demographic variables (gender, age, education, income, marital status and occupation); consumer shopping orientations (convenience - oriented, price - oriented, experiential - oriented and impulsiveness) and product categories (fresh food, non-perishable food, household as well as health and beauty) were above the recommended level of 0.7 , which indicates a satisfactory internal consistency reliability (Hair et al., 2010). 
Table 1: Cronbach's $\alpha$ and composite reliability

\begin{tabular}{|l|l|l|}
\hline Constructs & Cronbach's $\boldsymbol{C}$ & $\boldsymbol{C R}^{*}$ \\
\hline Gender & 1.00 & 1.00 \\
Age & 1.00 & 1.00 \\
Education & 1.00 & 1.00 \\
Income & 1.00 & 1.00 \\
Marital status & 1.00 & 1.00 \\
Occupation & 1.00 & 1.00 \\
Convenience - oriented & 0.884 & 0.916 \\
Price - oriented & 0.840 & 0.887 \\
Experiential - oriented & 0.751 & 0.859 \\
Impulsiveness & 0.73 & 0.751 \\
Fresh food & 0.886 & 0.949 \\
Non-perishable food & 0.944 & 0.952 \\
Household & 0.916 & 0.947 \\
Health and beauty & 0.886 & 0.912 \\
\hline
\end{tabular}

\section{CR: composite reliability}

The results in Table 2 show that the average variance extracted (AVEs) are above the recommended level of 0.5 . Consequently, they can be considered as an indicator for adequate convergent validity (Hair et al., 2010). Based on these results, it can be concluded that the latent variables have a satisfactory convergent validity.

Table 2: Average variance extracted (AVE)

\begin{tabular}{|l|l}
\hline$\underline{\text { Constructs }}$ & $\underline{\boldsymbol{A V E}}$ \\
\hline Gender & 1.00 \\
Age & 1.00 \\
Education & 1.00 \\
Income & 1.00 \\
Marital status & 1.00 \\
Occupation & 1.00 \\
Convenience - oriented & 0.685 \\
Price - oriented & 0.611 \\
Experiential - oriented & 0.671 \\
Impulsiveness & 0.601 \\
Fresh food & 0.699 \\
Non-perishable food & 0.623 \\
Household & 0.857 \\
Health and beauty & 0.623
\end{tabular}

AVE: average variance extracted

The following Table 3 shows that all of the square roots of AVEs are higher than the correlation of that relevant construct. This means that, the values on the diagonal are larger than any of the values below or above them in the same column and larger than any of the values to their right or left in the same row (Kock, 2012). Therefore, it can be concluded that the discriminant validity is acceptable for each latent variable. 
Table 3: Square roots of average variances extracted (AVEs)

\begin{tabular}{|c|c|c|c|c|c|c|c|c|c|c|c|c|c|c|}
\hline & Gender & Age & Education & Income & \begin{tabular}{|l} 
Marital \\
status
\end{tabular} & Occup. & Convenience-O & Price-O. & Experiential-O & \begin{tabular}{|l} 
Impulsiv- \\
ness
\end{tabular} & $\mid \begin{array}{l}\text { Fresh } \\
\text { Food }\end{array}$ & $\mid \begin{array}{l}\text { Non-per. } \\
\text { Food }\end{array}$ & Household & $\mid \begin{array}{l}\text { Health\& } \\
\text { beauty }\end{array}$ \\
\hline Gender & $(1.000)$ & -0.207 & 0.057 & -0.185 & 0.210 & 0.135 & -0.230 & -0.295 & 0.044 & -0.128 & 0.003 & -0.086 & -0.030 & -0.005 \\
\hline Age & -0.207 & $(1.000)$ & 0.074 & 0.472 & -0.565 & -0.367 & 0.178 & 0.197 & -0.022 & 0.138 & 0.133 & 0.208 & 0.132 & 0.113 \\
\hline Education & 0.057 & 0.074 & $(1.000)$ & 0.255 & -0.089 & -0.013 & 0.070 & 0.001 & -0.007 & -0.003 & 0.085 & 0.125 & 0.044 & 0.069 \\
\hline Income & -0.185 & 0.472 & 0.255 & $(1.000)$ & -0.481 & -0.401 & 0.228 & 0.088 & -0.004 & 0.068 & 0.052 & 0.231 & 0.215 & 0.232 \\
\hline Marital status & 0.210 & -0.565 & -0.089 & -0.481 & $(1.000)$ & 0.327 & -0.073 & -0.128 & -0.098 & -0.147 & -0.098 & -0.220 & -0.173 & -0.190 \\
\hline Occupation & 0.135 & -0.367 & -0.013 & -0.401 & 0.327 & $(1.000)$ & -0.004 & -0.024 & -0.063 & -0.214 & -0.058 & -0.162 & -0.132 & -0.093 \\
\hline Convenience-O. & -0.230 & 0.178 & 0.070 & 0.228 & -0.073 & -0.004 & $(0.828)$ & 0.628 & -0.392 & 0.081 & 0.298 & 0.468 & 0.441 & 0.336 \\
\hline Price-O. & -0.295 & 0.197 & 0.001 & 0.088 & -0.128 & -0.024 & 0.628 & $(0.782)$ & -0.285 & 0.277 & 0.298 & 0.358 & 0.291 & 0.266 \\
\hline Experiential-O. & 0.044 & -0.022 & -0.007 & -0.004 & -0.098 & -0.063 & -0.392 & -0.285 & $(0.819)$ & 0.067 & -0.457 & -0.350 & -0.253 & -0.164 \\
\hline Impulsiveness & -0.128 & 0.138 & -0.003 & 0.068 & -0.147 & -0.214 & 0.081 & 0.277 & 0.067 & $(0.693)$ & 0.075 & 0.211 & 0.165 & 0.198 \\
\hline Fresh Food & 0.003 & 0.133 & 0.085 & 0.052 & -0.098 & -0.058 & 0.298 & 0.298 & -0.457 & 0.085 & $(0.836)$ & 0.277 & 0.291 & 0.266 \\
\hline Non-per. Food & -0.086 & 0.208 & 0.125 & 0.231 & -0.220 & -0.162 & 0.468 & 0.358 & -0.350 & 0.211 & 0.277 & $(0.789)$ & 0.165 & 0.232 \\
\hline Household & -0.030 & 0.132 & 0.044 & 0.215 & -0.173 & -0.132 & 0.441 & 0.291 & -0.253 & 0.165 & 0.291 & 0.165 & $(0.926)$ & 0.069 \\
\hline Health \& beauty & -0.005 & 0.113 & 0.069 & 0.232 & -0.190 & -0.093 & 0.336 & 0.266 & -0.164 & 0.198 & 0.266 & 0.232 & 0.069 & $(0.756)$ \\
\hline
\end{tabular}

\subsection{Structural model}

The structural model is used to measure the causal relationships among the constructs. Four models were tested, to investigate how demographic variables and consumer shopping orientations affect the purchasing preference for different product categories (fresh food, non-perishable food, household products and health \& beauty products) in the context of online grocery shopping (Figures 2, 3, 4 and 5).

\subsubsection{Demographic variables:}

\section{- Gender}

As shown in figure 2, 3, 4 and 5, the gender has a significant positive effect on each of the four product categories. These results support hypothesis H1.

- Age

It was found that age has no significant influence on fresh food and non-perishable food online. However, it was found that age has a significant positive impact on the household $(\beta=0.12, \mathrm{P}<0.02)$ as well as health $\&$ beauty $(\beta=0.14, \mathrm{P}<0.02)$. The hypothesis $\mathrm{H} 2$ can be accepted for household products and health $\&$ beauty products.

- Education

It was found that education has a positive effect on fresh food products $(\beta=0.12, \mathrm{P}<0.02)$ and non-perishable food products $(\beta=0.16, \mathrm{P}<0.01)$. In contrast, it was found that education has a negative impact on household $(\beta=-$ $0.14, \mathrm{P}<0.01)$ and health $\&$ beauty $(\beta=-0.20, \mathrm{P}<0.01)$. Consequently, these findings support the hypothesis $\mathrm{H} 3$.

\section{- Household income}

The results of the study found that household income had no significant impact on fresh food products and nonperishable food products. However, it has a significant positive influence on household products $(\beta=0.17$, $\mathrm{P}<0.01)$ and health $\&$ beauty products $(\beta=0.20, \mathrm{P}<0.01)$. This validates the hypothesis 4 for these two product categories.

\section{- Marital Status}

As shown in figure 2, 3, 4 and 5, the marital status has a significant negative impact on fresh food, nonperishable food, household products and health \& beauty products. Consequently, these findings support the hypothesis $\mathrm{H} 5$ for each of the product categories.

\section{- Occupation}

It was found that occupation has no significant impact on the fresh food and health $\&$ beauty products. However, the results indicate that occupation has a significant negative impact on non-perishable food $(\beta=-0.14, P<0.01)$ and household products $(\beta=-0.13, \mathrm{P}<0.02)$. The hypothesis $\mathrm{H} 6$ can be accepted for non-perishable food and household products.

\subsubsection{Consumers Shopping Orientation:}

- Convenience-orientation

It was found that convenience-orientation has a significant positive impact on the fresh food $(\beta=0.14, \mathrm{P}<0.01)$, non-perishable food $(\beta=0.28, \mathrm{P}<0.01)$, household products $(\beta=0.29, \mathrm{P}<0.01)$ and health $\&$ beauty products $(\beta=0.23, \mathrm{P}<0.01)$. Consequently, these findings support the hypothesis $\mathrm{H} 7$ for each of the four product 
categories.

\section{- Price-orientation}

The results of the study indicate that price-orientation has a significant positive impact on fresh food $(\beta=0.13$, $\mathrm{P}<0.01)$, non-perishable food $(\beta=0.16, \mathrm{P}<0.01)$ and health $\&$ beauty products $(\beta=0.17, \mathrm{P}<0.01)$. However, it has a significant negative impact on household products $(\beta=-0.16, \mathrm{P}<0.01)$. Based on these findings, the hypothesis 8 can be supported for each of the four product categories.

\section{- Experiential-orientation}

The results of the study show that experiential-orientation has significant negative impact on fresh food $(\beta=-$ $0.35, \mathrm{P}<0.01)$, non-perishable food $(\beta=-0.18, \mathrm{P}<0.01)$ and household products $(\beta=-0.10, \mathrm{P}<0.05)$. However, the results indicate that experiential-orientation does not affect health and beauty products. These validate the hypothesis for fresh food, non-perishable food and household products.

\section{- Impulsiveness}

The results on the impact of impulsiveness on the purchasing preference for different product categories show that impulsiveness has a significant positive impact on non-perishable food $(\beta=0.13, \mathrm{P}<0.01)$, household products $(\beta=0.14, \mathrm{P}<0.01)$ and health $\&$ beauty products $(\beta=0.10, \mathrm{P}<0.04)$. However, it was found that impulsiveness does not significantly affect fresh food. The hypothesis H10 can be accepted for non-perishable food, household products and health \& beauty products.

For r-squared coefficients $\left(\mathrm{R}^{2}\right)$ it was found that together gender, education, marital status, convenienceorientation, price-orientation and experiential-orientation explained $32 \%$ of the variance in fresh food (see figure 2).

\section{Figure 2: Structural model for fresh food}



For non-perishable food the results indicate that together gender, education, marital status, occupation, convenience-orientation, price-orientation, experiential-orientation and impulsiveness explained $43 \%$ of the variance in non-perishable food product, as shown in figure 3. 
Figure 3: Structural model for non-perishable food

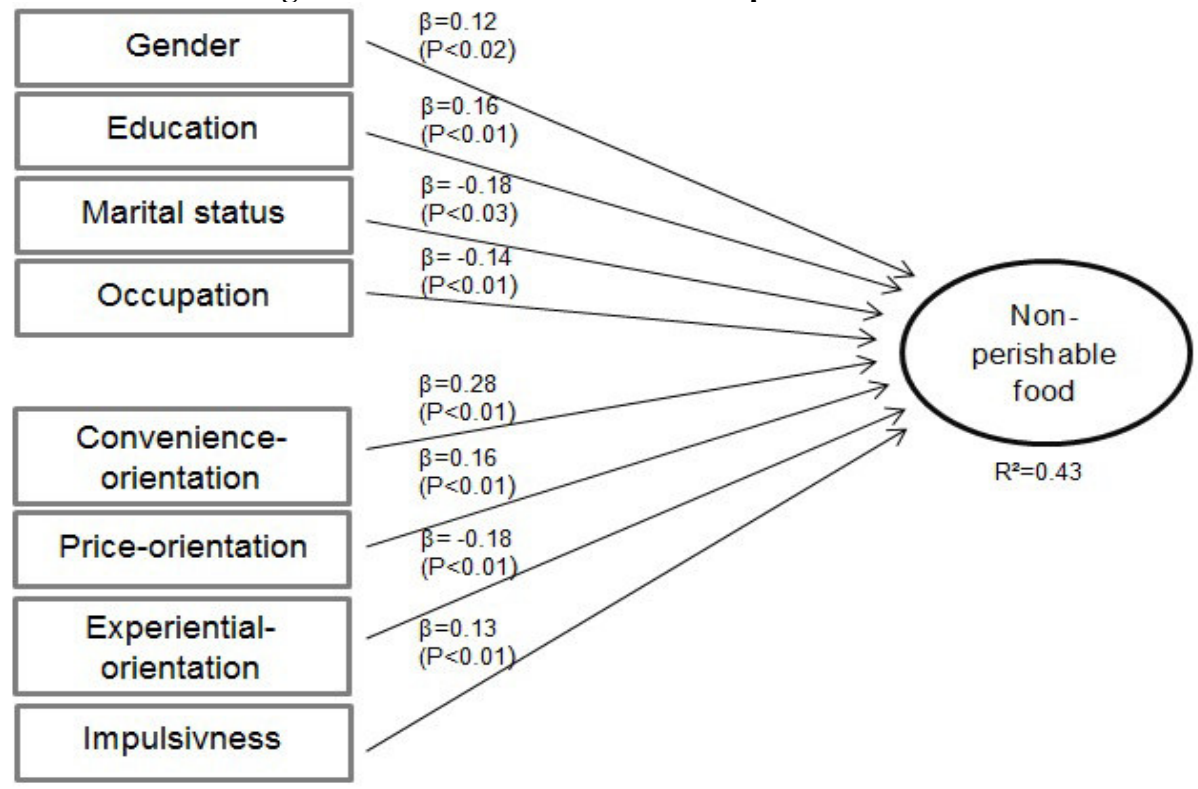

Regarding household products, it was found that together gender, age, education, income, marital status, occupation, convenience - oriented, price - oriented and experiential - oriented and impulsiveness explained $26 \%$ of the variance (see figure 4 ).

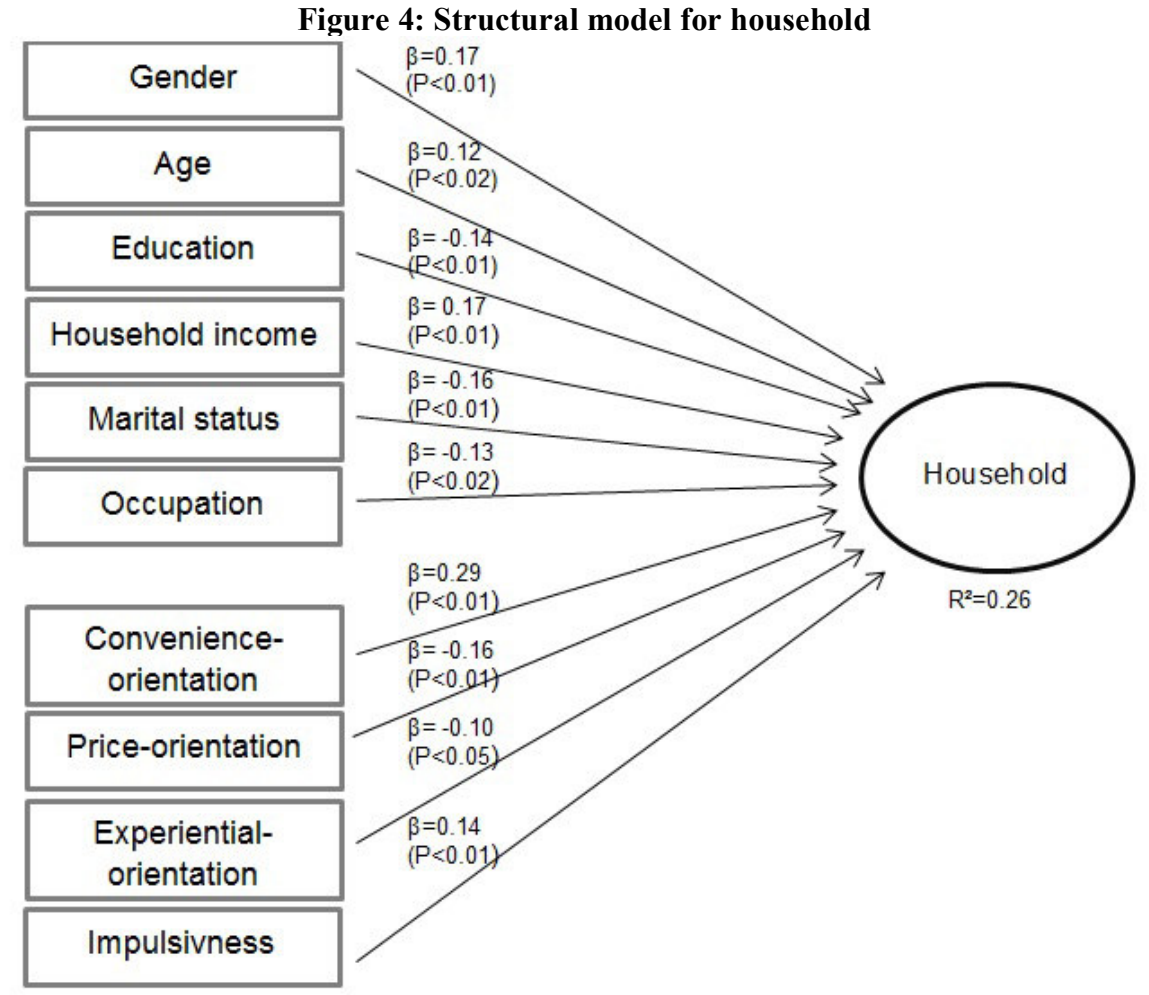

Regarding $\mathrm{R}^{2}$ for health \& beauty products, it was found that together gender, age, education, income, marital status, convenience-orientation, price-orientation and impulsiveness explained $27 \%$ of the variance, as shown in figure 5. 
Figure 5: Structural model for health $\&$ beauty

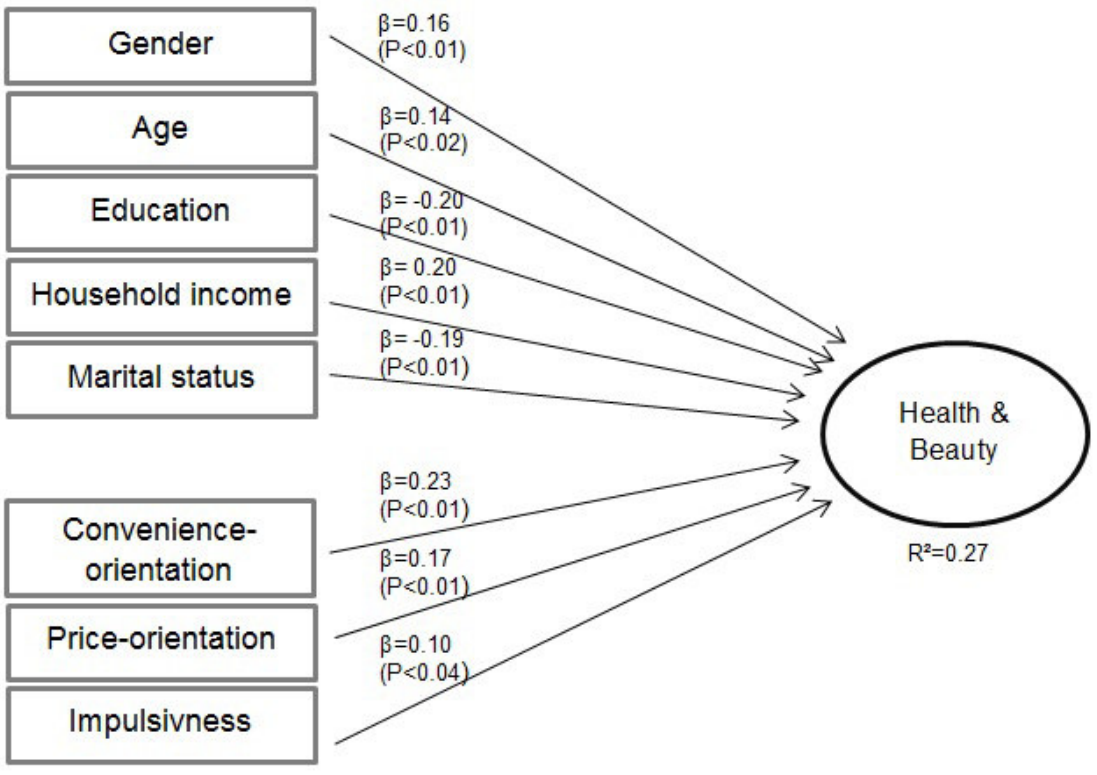

\section{Discussion}

\section{- Demographic variables}

The findings provide evidence that females are more willing to purchase groceries online, particularly household products and health \& beauty products. This corresponds to the results of several researchers, who suggested the gender had a significant impact on the preference to purchase certain products (Haque et al., 2007; Hasan, 2010). Based on the findings, it appears that men perceive online grocery shopping not as practical and less advantageous as females do. Further, these findings indicate that groceries are more suitable to be sold to females, especially household and health \& beauty products. The nature of these products seems to attract females to purchase them online, rather buying them in store.

For age, the results of this study indicate that age has no significant influence on fresh food and nonperishable food online. However, it was found that age has a significant positive impact on the household as well as health \& beauty. These results are different from those of Joines et al. (2003) who found that the adoption of online shopping is negatively influenced by an increasing consumer age. On the other hand, education has an effect on fresh food products, non-perishable food products, household and health \& beauty. These results go in line with the findings of Kim and Kim (2004) and Koyuncu and Lien (2003).

For household income, the results of the study found that household income has no significant impact on fresh food products and non-perishable food products. However, it has an impact on household products and health \& beauty products. These findings are in line with Monsuwé et al. (2004) who found that household income had an impact on shop online. In addition, the results of the study indict that marital status has an impact on fresh food, non-perishable food, household products and health \& beauty products. This result goes in line with the findings of Brown and Venkatesh (2005) who found that marital status had impact on online shopping. Moreover, study results found that occupation has no significant impact on the fresh food and health \& beauty products. These findings are in line with Blake et al. (2003) who found that occupation of consumers had no significant impact on their online shopping behaviour. However, the results indicate that occupation has a significant impact on non-perishable food and household products.

\section{- Consumer shopping orientations}

The results of study demonstrate that convenience-orientation has a significant positive impact on the fresh food, non-perishable food, household products and health \& beauty products. This result is consistent with Donthu and Garcia (1999) who found that online shoppers are more convenience-oriented compared to traditional shoppers. In addition, Jarvenpaa and Todd (1997) reported that convenience is the most significant perceived benefit of online shopping. Moreover, the results of the study reveal that price-orientation has a significant impact on fresh food, non-perishable food, health \& beauty products and household products. These results confirm the findings of Donthu and Garcia (1999) and Li et al. (1999), that price has a significant motive to conduct online purchases. It also adheres with Zhou et al. (2004) findings, they found in their study that price-oriented consumers are always seeking to buy products for the lowest price or trying to get the best value for their expenses. For 
experiential-orientation, the results of the study indicate that experiential-orientation has significant negative impact on fresh food, non-perishable food and household products. These findings support prior studies by Li et al. (1999) who found that an experiential orientation negatively influences the likeness to conduct online purchases, since the experiential orientation focuses on interacting with products. Within the online environment it is not possible to experience the products, which means examining the physical condition of the product by touching, feeling or smelling it. However, the results indicate that experiential-orientation does not affect health and beauty products. Regarding impulsiveness, the results of study demonstrate that impulsiveness has a significant positive impact on non-perishable food, household products and health \& beauty products. These results confirm the findings of Donthu and Garcia (1999) found in their study on online shopping behaviour that Internet shoppers are more impulsive compared to non-internet-shoppers. However, it was found that impulsiveness does not significantly affect fresh food. This result is in contrast to Girard et al. (2003) study, which found that impulsive purchases are more likely to be for inexpensive products.

\section{Conclusions}

This research attempted to examine the impact of demographic variables and consumer shopping orientations on the purchasing preference for different product categories in the context of online grocery shopping. A comprehensive review of the literature in the area of online shopping has shown that demographic variables such as age, gender, education, household income, marital status and occupation have influence on the online shopping behaviour of consumers. The recent literature also indicated a significant impact of the consumers' shopping orientation on the online shopping behaviour. This research has built upon these prior studies by examining the impact of demographic variables and consumer shopping orientations on the preference to purchase within certain product categories in the context of online grocery shopping. It was found that the role of product categories was mostly neglected in earlier studies, although many researches have emphasised the decisive role of product categories on the online shopping behaviour (Bhatnagar et al., 2000; Liao and Cheung, 2001; Lian and Lin, 2008). Research that explicitly examines the influence of demographics and consumer shopping orientations on a product level, particularly related to groceries, is scarce and further research is needed to address this gap in the literature.

First of all, the results from the structural equation model indicated that demographic variables have significant impact on preference to purchase certain products online. However, it has to be noted that the results vary among the four different product categories. The findings showed that demographic variables gender, education and marital status have significant impact on the preference to purchase fresh food, non-perishable food, household products and health \& beauty products online. The results on household income and occupation vary among the different product categories. It was found that household income of consumers has significant impact on the preference to purchase household products and health \& beauty products online. However, no significant impact on the preference to purchase fresh food and non-perishable food online could be observed. For occupation the findings indicate no significant impact on the preference to purchase fresh food and health $\&$ beauty products online. However, the results indicate that occupation has a significant influence on the preference to purchase non-perishable food and household products online. Therefore, it can be concluded that demographic variables have a significant influence on the preference to purchase certain products online and that the correlations between the respective constructs vary by product category as described above.

Regarding the influence of the shopping orientation of consumers on the preference to purchase certain product, the results indicate convenience-orientation, price-orientation significantly affect the preference to purchase fresh food, non-perishable food, household products and health \& beauty products online. It was also found that the preferences vary by product category. Further, a significant influence of experiential-orientation on the preference to purchase fresh food, non-perishable food and household products could be observed. However, no significant influence of experiential-orientation could be found for the preference to purchase health \& beauty products online. Regarding the impact of impulsiveness, the findings indicate a significant influence on the preference to purchase non-perishable food, household products and health $\&$ beauty products online. However, no significant influence could be found for the preference to purchase fresh food online. Based on these results, it can be concluded that the shopping orientation of consumers has a significant influence on the preference to purchase certain products online. The preferences vary among the different shopping orientations and also vary by product category.

In summary, the results of this research provided evidence that demographic variables and consumer shopping orientations have impacts on the preference to purchase certain products online. The findings show that the purchasing preferences vary by product category depending on the demographic variables and the consumer shopping orientations.

\section{Reference}

Aaker, D.A., Kumar, V. and Day, G. (2006) Marketing Research, New York: Wiley. 
Armstrong, G. and Kotler, P. (2003) Marketing: An Introduction, Pearson Education International.

Bakos, Y.J. (1997) 'Reducing Buyer Search Costs: Implications for Electronic Marketplaces', Management Science, vol. 43, no. 12, p. 1676-1692.

Bellman, S., Lohse, G.L. and Johnson, E.J. (1999) 'Predictors of Online Buying Behavior', Communications of the $A C M$, vol. 42 , no. 12 , pp. 32-38.

Bhatnagar, A., Misra, S. and Rao, R. (2000) 'On Risk, Convenience, and Internet Shopping Behavior', Communications of the ACM, vol. 43, no. 11, pp. 98-105.

Blake, B.F., Neuendorf, K.A. and Valdiserri, C.M. (2003) 'Innovativeness and variety of internet shopping', Internet Research-Electronic Networking Applications and Policy, vol. 13, no. 3, pp. 156-169.

Brown, S.A. and Venkatesh, V. (2005) 'Model of adoption of technology in household: A baseline model test and extension incorporating household life cycle', MIS Quarterly, vol. 29, no. 3, pp. 399-426.

Brown, M., Pope, N. and Voges, K. (2003) 'Buying or browsing?: An exploration of shopping orientations and online purchase intention', European Journal of Marketing, vol. 37, no. 11/12, pp. 1666-1685.

Burroughs, R.E. and Sabherwal, (2001) 'Determinants of retail electronic purchasing: a multi-period investigation', Journal of Information System Operation Research, vol. 40, no. 1, pp. 35-56.

Chu, J., Arce-Urriza, M., Cebollada-Calvo, J.-J. and Chintagunta, P.K. (2010) 'An Empirical Analysis of Shopping Behavior Across Online and Offline Channels for Grocery Products: The Moderating Effects of Household and Product Characteristics', Journal of Interactive Marketing, vol. 24, pp. 251-268.

Evolution (2012) Online Food and Grocery: The Shopper Perspective 2012, [Online], Available: HYPERLINK "http://de.slideshare.net/evolutioninsights/online-2012-sample-extract" http://de.slideshare.net/evolutioninsights/online-2012-sample-extract [07 June 2018].

Dholakia, R.R. and Uusitalo, O. (2002) 'Switching to electronic stores: Consumer characteristics and the perception of shopping benefit', International Journal of Retail \& Distribution Management, vol. 30, no. 10, pp. $459-469$.

Donthu, N. and Garcia, A. (1999) 'The Internet Shopper', Journal of Advertising Research, vol. 39, no. 3, pp. 5258.

Garson. D. (2008). 'Structural Equation Modeling' from Statnotes: Topics in Multivariate Analysis. North Carolina State University, Retrieved August 15, 2014. http://www.statisticalassociates.com/assumptions.pdf

Gefen, D., Straub, D. W., and Boudreau, M.-C. 2000. "Structural Equation Modeling and Regression: Guidelines for Research Practice," Communications of the Association for Information Systems, vol. 4, no 7, pp. 1-70

Girard, T., Korgaonkar, P. and Silverblatt, R. (2003) 'Relationship of type of Product, shopping orientations, and demographics with preference for shopping on the internet', Journal of Business and Psychology, vol. 18, no. 1, pp. 101-120.

Goldsmith, R.E. and Flynn, L.R. (2005) 'Bricks, clicks, and pix: Apparel buyers ' use of stores, internet, and catalogs compared', International Journal of Retail \& Distribution Management, vol. 33, no. 4, pp. 271283.

Hair, J. F., Jr., W. C. Black, B. J. Babin, and R. E. Anderson. (2010). Multivariate Data Analysis. 7th ed. Upper Saddle River, NJ: Pearson.

Hansen, T. (2004) 'Consumer values, the theory of planned behaviour and online grocery shopping', International Journal of Consumer Studies, vol. 32, pp. 128-137.

Haque, A., Mahmud, S.A., Tarofder, A.K. and Ismail, A.Z.H. (2007) 'Internet advertisement in Malaysia: A study on attitudinal differences', The Electronic Journal on Information Systems in Developing Countries, vol. 31 , no. 9 , pp. 1-15.

Hasan, B. (2010) 'Exploring gender differences in online shopping attitude', Computers in Human Behavior, vol. 26, pp. 597-601.

Hashim, A., Ghani, E.K. and Said, J. (2009) 'Does Consumers' Demographic Profile Influence Online Shopping?: An Examination Using Fishbein's Theory', Canadian Social Science, vol. 5, no. 6, pp. 19-31.

Jarvenpaa, S.L. and Todd, P.A. (1997) 'Consumer Reactions to Electronic Shopping on the World Wide Web', International Journal of Electronic Commerce, vol. 1, no. 2, pp. 59-88.

Joines, J.L., Scherer, C.W. and Scheufele, D.A. (2003) 'Exploring motivation for consumer web use and their implication for e-commerce', Journal of Consumer Marketing, vol. 20, no. 2, pp. 90-108.

Kim, E.Y. and Kim, Y.K. (2004) 'Predicting online purchase intention for clothing products', European Journal of Marketing, vol. 38, no. 7, pp. 883-897.

Kock, N. 2012. WarpPLS 3.0 user manual, Laredo, Texas, ScriptWarp ystems.

Koyuncu, C. and Lien, D. (2003) 'E-commerce and consumer's purchasing behaviour', Applied Economic, vol. 35 , no. 6 , pp. 721-726.

Li, H., Kuo, C. and Rusell, M.G. (1999) 'The Impact of Perceived Channel Utilities, Shopping Orientations, and Demographics on the Consumer's Online Buying Behavior', Journal of Computer-Mediated Communication, vol. 5, no. 2. 
Lian, J.-W. and Lin, T.-M. (2008) 'Effects of consumer characteristics on their acceptance of online shopping: Comparisons among different product types', Computers in Human Behavior, vol. 24, pp. 48-65.

Liao, Z. and Cheung, M.T. (2001) 'Internet-based e-shopping and consumer attitudes: an empirical study', Information \& Management, vol. 38, pp. 299-306.

Lohse, G.L. and Spiller, P. (2000) 'Internet retail store design: how the user interface influences traffic and sales', Journal of Computer Mediated Communication, vol. 5, no. 2, pp. 219-234.

Mahmood, M.A., Bagchi, K. and Ford, T.C. (2004) 'On-Line Shopping Behavior: Cross-Country Empirical Research', International Journal of Electronic Commerce, vol. 9, no. 1, pp. 9-30.

Monsuwé, T.P., Dellaert, B.G.C. and de Ruyter, K. (2004) 'What drives consumer to shop online? A literature review', International Journal of Service Industry Management, vol. 15, no. 1, pp. 102-121.

Netemeyer, R., Bearden, W. \& Sharma, S. 2003. Scaling procedures: issues and applications, London, Sage Publications.

Nielsen UK (2012) Marketing Magazine, [Online], Available: HYPERLINK "http://www.marketingmagazine.co.uk/article/1158155/uk-online-grocery-sales-surge-consumers-seekvalue" http:/www.marketingmagazine.co.uk/article/1158155/uk-online-grocery-sales-surge-consumersseek-value [06 June 2018].

Sulaiman, A., Ng, J. and Mohezar, S. (2008) ' E-Ticketing as a new way of buying tickets: Malaysian perceptions', Journal of Social Science, vol. 17, no. 2, pp. 149-157.

Susskind, A.M. (2004) 'Electronic Commerce and World Wide Web Apprehensiveness: An Examination of Consumers' Perceptions of the World Wide Web', Journal of Computer-Mediated Communication, vol. 9, no. 3 .

Rohm, A.J. and Swaminathan, V. (2004) 'A typology of online shoppers based on shopping motivations', Journal of Business Research, no. 57, pp. 748- 757.

Zhou, L., Chiang, W.Y. and Zhang, D. (2004) 'Discovering Rules for Predicting Customers' Attitude Toward Internet Retailers', Journal of Electronic Commerce Research, vol. 5, no. 4, pp. 228-238. 